\title{
Pemanfaatan Mikrobia Pengurai dan Probiotik dalam Budidaya Ikan Gurame di Desa Trimulyo Kabupaten Bantul
}

\author{
Eman Darmawan \\ E-mail: emandarma67@gmail.com \\ Prodi Teknologi Pangan \\ Fakultas Sains dan Teknologi Universitas Widya Mataram
}

\begin{abstract}
In conducting carp cultivation, farmers form a group of carp cultivation as their parent organization, making it easier for them to manage fish, feed, water needs, facilities and infrastructure for fish farming. However, in reality, farmers are still having problems in doing carp cultivation, namely the quality of pond water decreases due to high ammonia levels, so the $\mathrm{pH}$ of pond water is low, fungi grow easily, and the mortality rate of fish is quite high, and slow growth of carp due to lust eat less carp.

The implementation method in solving problems faced by carp fish farmer groups is classical and practical. Based on the evaluation results showed that the ability of fish farmers in the technique of carp cultivation increased, interest to apply the utilization of microbial decomposers in carp cultivation was quite high, entrepreneurial spirit of members of farmer groups experienced an increase, and were able to innovate in fish farming tech
\end{abstract}

Keywords: carp, decomposing microbes, nutrients

\begin{abstract}
ABSTRAK
Dalam melakukan budidaya ikan gurame, petani membentuk kelompok tani budidaya ikan gurame sebagai organisasi induk mereka sehingga memudahkan mereka dalam pegelolaan ikan, pakan, kebutuhan air, sarana dan prasarana budidaya ikan. Akan tetapi pada kenyataannya petani masih banyak mengalami kendala dalam melakukan budidaya ikan gurame, yaitu kualitas air kolam menurun yang disebabkan kadar amoniaknya tinggi, sehingga $\mathrm{pH}$ air kolam rendah, mudah ditumbuhi jamur, dan tingkat kematian ikan cukup tinggi, serta lambatnya pertumbuhan ikan gurame karena nafsu makan ikan gurame kurang.

Metode pelaksanaan dalam memecahkan permasalahan yang dihadapi oleh kelompok tani ikan gurame adalah secara klasikal dan praktek. Berdasarkan hasil evaluasi menunjukkan bahwa kemampuan petani ikan dalam teknis budidaya ikan gurame mengalami peningkatan, animo untuk mengaplikasikan pemanfaatan
\end{abstract}


mikrobia pengurai dalam budidaya ikan gurame cukup tinggi, jiwa wirausaha para anggota kelompok tani mengalami peningkatan, dan mampu melakukan inovasi dalam teknologi budidaya ikan.

Kata kunci: ikan gurame, mikrobia pengurai, dan nutrisi.

\section{Pendahuluan}

Desa Trimulyo merupakan salah satu desa perkotaan di Kecamatan Jetis Kabupaten Bantul, memiliki luas wilayah 710,45 hektar yang terdiri dataran rendah dan perbukitan, serta dipisahkan oleh sungai opak. Mata pecaharian masyarakat di Desa Trimulyo masih didominasi petani karena memiliki tanah yang subur dan aliran air irigasi teknis.

Pasca gempa bumi Bantul tahun 2006 usaha pemberdayaan masyarakat terus digalakkan, salah satunya adalah dengan memanfaatkan aliran sungai Opak di Dusun Blawong I Trimulyo Jetis Bantul untuk membudidayakan ikan tawar khususnya ikan gurame. Usaha budidaya ikan gurame harapannya bagi warga masyarakat dapat memberikan tambahan penghasilan yang sangat membantu ekonomi keluarga sehingga perkembangan dan jumlah kolam yang membudiyakan ikan gurame mencapai 20 kolam. Dalam melakukan budidaya ikan gurame, petani membentuk kelompok tani budidaya ikan gurame sebagai organisasi induk mereka, sehingga memudahkan mereka dalam pengelolaan ikan, pakan, kebutuhan air, sarana dan prasarana budidaya ikan.

Akan tetapi pada kenyataannya petani masih banyak mengalami kendala dalam melakukan budidaya ikan gurame, yaitu disebabkan kualitas air kolam menurun. Menurut Santosa, 1999 menurunnya kualitas air disebabkan kadar amoniak kolam meningkat sehingga $\mathrm{pH}$ air kolam rendah, mudah ditumbuhi jamur, dan mengakibatkan kematian ikan cukup tinggi serta lambatnya pertumbuhan ikan gurame karena nafsu makan ikan gurame kurang. Berdasarkan pengamatan tersebut, kami akan melakukan transfer IPTEK untuk memperbaiki proses budidaya ikan 
gurame dengan penerapan mikrobia pengurai dan probiotik dalam budidaya ikan gurame, perbaikan kualitas air kolam dan perbaikan sistem manajemen/tata kelola budidaya ikan. Pemanfaatan probiotik dalam budidaya ikan mampu menperbaiki kondisi air kolam melalui proses degradasi bahan organik, sehingga menghasilkan zat-zat yang bermanfaat bagi pertumbuhan plankton (Hartini., dkk, 2013). Dengan demikian petani budidaya ikan gurame benar-benar dapat meningkatkan kesejahteraannya. Tujuan dari kegiatan pengabdian ini adalah meningkatkan kemampuan kelompok tani budidaya ikan gurame dalam teknologi budidaya ikan gurame dengan memamfaatkan mikrobia pengurai dan probiotik.

\section{Metode Pelaksanaan}

Berbagai permasalahan yang dihadapi oleh kelompok tani ikan gurame perlu segera diatasi dengan menawarkan solusi untuk mengatasi permasalahan tersebut dengan sentuhan ipteks melalui kegiatan pemamfaatan mikrobia pengurai dan probiotik dalam budidaya ikan gurame.

Pendekatan dalam penyampaian materi pelatihan dan pola penyelesaian masalah adalah secara klasikal dan praktek.

\section{Hasil dan Pembahasan}

1. Pelatihan budidaya ikan gurame dengan memanfaatkan peranan mikrobia pengurai dan probiotik

Pelatihan budidaya ikan gurame dengan memanfaatkan peranan mikrobia pengurai dan probiotik merupakan sebagai upaya untuk meningkatkan kualitas air kolam dengan menguraikan kotoran ikan melalui proses nitrifikasi mengubah ammonia menjadi nitrat sehingga dapat dikonsumsi ikan gurame sebagai pakan tambahan dan memperbaiki kualitas air. Amoniak di alam akan dioksidasi menjadi bentuk nitrit $\left(\mathrm{NO}_{2}^{-}\right)$dan kemudian menjadi nitrat $\left(\mathrm{NO}_{3}^{-}\right)$yang 
dilakukan oleh dua macam bakteri autotrop dalam proses yang disebut nitrifikasi. Amoniak sangat berguna bagi tumbuhan dan mikroorganisma untuk asimilasi menjadi sel baru yang memberikan lebih banyak nitrogen organik (Widayat., $\mathrm{dkk}, 2010)$.

Materi yang diberikan pada saat pelatihan adalah pengenalan mikrobia pengurai dan probiotik, peranan mikrobia dalam meningkatkan kualitas air, teknis penggunaan mikrobia, perawatan kolam dan masa panen. Kegiatannya seperti terlihat pada Gambar 1.

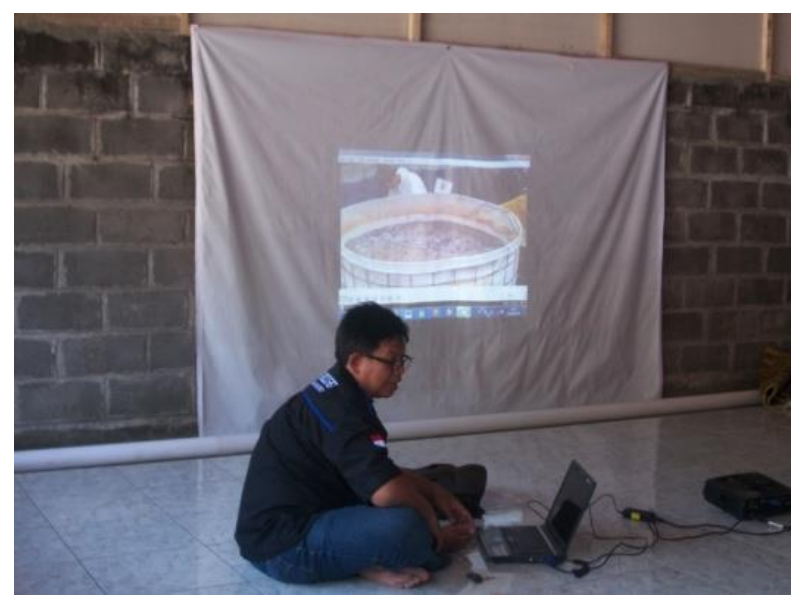

Gambar 1. Penyuluhan aplikasi penggunaan mikrobia pengurai dan probiotik dalam kolam.

2. Pelatihan penggunaan pupuk organic (POC), hormonik dan viterna pada pakan.

Materi pelatihan menyangkut peranan pupuk organik, hormonik dan viterna dalam memenuhi kebutuhan mikro nutrien dan hormon untuk meningkatkan nafsu makan ikan sehingga peningkatan berat badan ikan gurame optimal. 

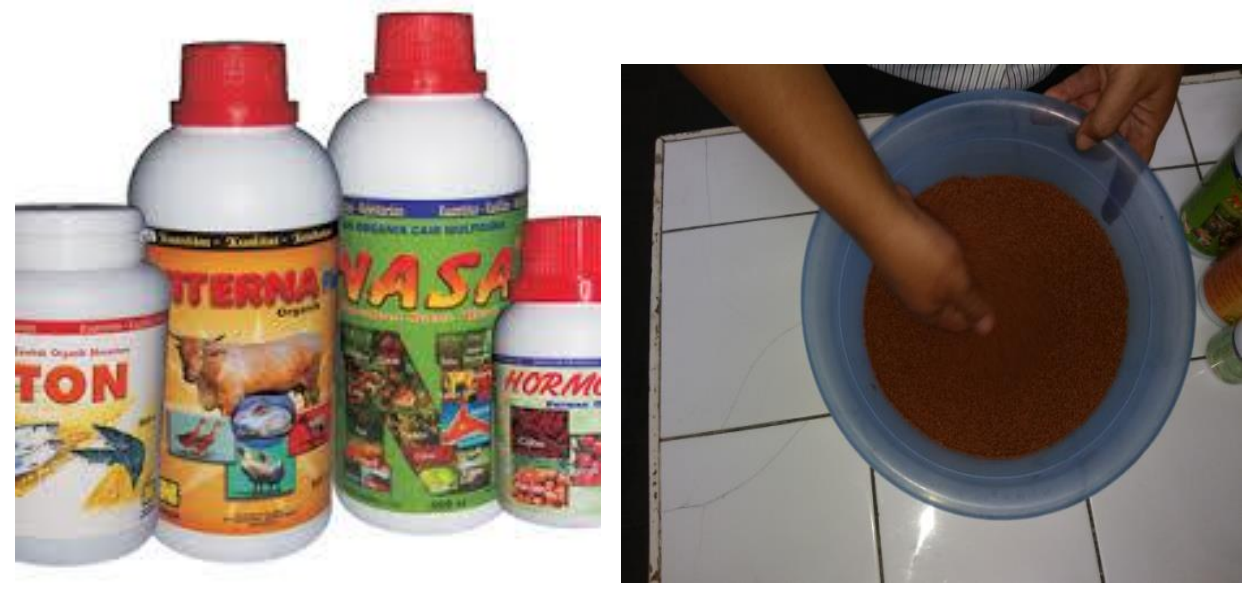

Gambar 2. Aplikasi pengkayaan nutrisi pakan

Pemberian tambahan mineral/mikro nutrien dan hormon dalam pakan sebagai upaya untuk meningkat kualitas pakan sehingga kebutuhan nutrisi ikan nya dapat terpenuhi. Dampaknya pertumbuhan ikan dapat tercapai dengan optimal dan lebih cepat.

3. Pelatihan manajemen/pengelolaan kolam

Pelatihan manajemen/pengelolaan kolam bertujuan untuk meningkatkan pengetahuan petani dalam pengelolaan kolam. Materi pelatihan berkaitan dengan pengertian manajemen, tatakelola kolam, jadwal pemberian pakan dan jumlah pakan yang akan digunakan.

Anggota kelompok tani menyadari betul tentang peranan penting dalam sistem tata kelola kolam harus dijalankan secara optimal agar efektif dan efisien dan hasilnya optimal. Petani sebelum melakukan budidaya ikan harus mampu membuat perencanaan, pengorganisasian, pengarahan dan pengendalian (Suryanan, 2003).

Petani menyadari bahwa dalam pemberian pakan tidak boleh asal, akan tetapi perlu diperhitungkan jumlah ikan dalam kolam maupun waktu pemberiannya pakan. Berat ikan harus ditimbang setiap minggunya agar jumlah pakan ikan yang diberikan jumlahnya tepat. 


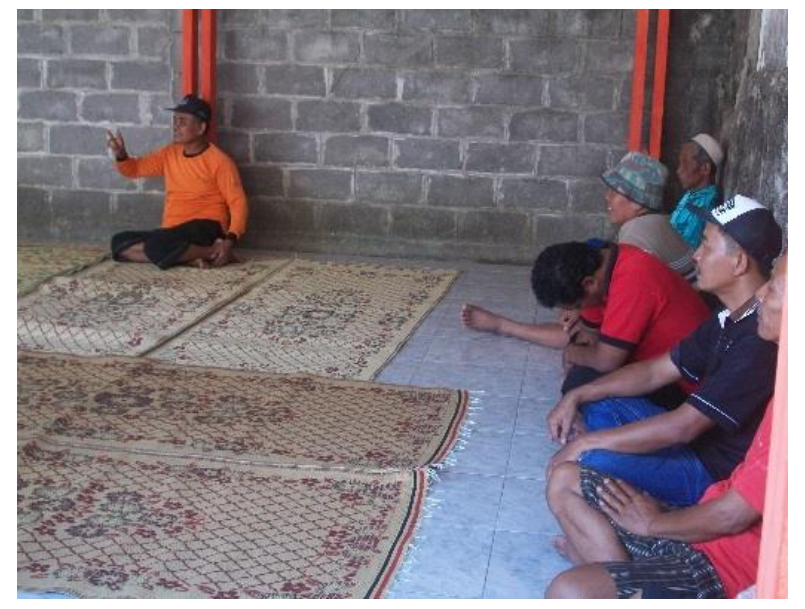

Gambar 3. Masyarakat antusias mengikuti pelatihan

\section{Kesimpulan}

Berdasarkan hasil pelaksanaan kegiatan pengabdian masyarakat maka dapat disimpulkan bahwa :

1. Kemampuan petani ikan dalam teknis budidaya ikan gurame mengalami peningkatan,

2. Animo untuk mengaplikasikan pemanfaatan mikrobia pengurai dalam budidaya ikan gurame cukup tinggi,

3. Mampu melakukan inovasi dalam teknologi budidaya ikan gurame. 


\section{DAFTAR PUSTAKA}

Hartini Sri, Dwi Sasanti Ade, Ferdinand Hukama Taqwa, 2013, Kualitas Air, Kelangsungan Hidup Dan Pertumbuhan Benih Ikan Gabus (Channa Striata) Yang Dipelihara Dalam Media Dengan Penambahan Probiotik, Jurnal Akuakultur Rawa Indonesia ISSN : 2303-2960, Palembang.

Santosa. B, 1999, Budidaya Ikan Nila Hitam, Kanisius, Yogyakarta.

Suryana, 2003, Kewirausahaan, Salemba Empat, Jakarta.

Widayat. W, Suprihatin dan Herlambang. A, 2010, Penyisihan Amoniak Dalam Upaya Meningkatkan Kualitas Air Baku Pdam-Ipa Bojong Renged Dengan Proses Biofiltrasi Menggunakan Media Plastik Tipe Sarang Tawon, JAI Vol 6. No. 1. Bogor. 